\title{
Erratum to: Field Study of Catch Basin Inserts for the Removal of Pollutants from Urban Runoff
}

\author{
Konstantinos Kostarelos • Eakalak Khan • \\ Nazzareno Callipo · Jennifer Velasquez
}

Published online: 18 August 2010

(C) Springer Science+Business Media B.V. 2010

\section{Erratum to: Water Resour Manage DOI 10.1007/s11269-010-9672-2}

In the original paper, Dave Graves was mistakenly credited as a co-author for this article.

His inclusion as a co-author is not a fault of the journal; his name was intentionally included by the primary author, Dr. Konstantinos Kostarelos.

We have corrected this as stated now.

The online version of the original article can be found under http://dx.doi.org/10.1007/s11269-010-9672-2.

K. Kostarelos $(\bowtie)$

Department of Civil and Environmental Engineering,

University of Cyprus, Nicosia, Cyprus

e-mail: dino@ucy.ac.cy

E. Khan

Department of Civil Engineering,

North Dakota State University,

Fargo, ND, USA

N. Callipo

Lockwood, Kessler \& Bartlett,

Syosset, NY, USA

J. Velasquez

NYC Department of Environmental Protection,

New York, NY, USA 